ArtefaCToS. Revista de estudios de la ciencia y la tecnología

eISSN: $1989-3612$

Vol. 8, No. 1 (2019), 2a Época, 82-96

DOI: http://dx.doi.org/10.14201/art2019818296

\title{
Una historia material de la ciencia y la tecnología: domesticación, laboratorios y registros*
}

\section{A Material History of Science and Technology: Domestication, Laboratories and Records}

\author{
Ana ROMERO DE PABLOS \\ Instituto de Filosofía, CSIC \\ ana.romero@cchs.csic.es \\ orcid.org/0000-0002-5911-5887
}

Recibido: 25/03/2019. Revisado: 03/04/2019. Aceptado: 14/04/2019

\section{Resumen}

En este artículo se proponen los repositorios científicos como sujetos y objetos epistemológicos para reflexionar sobre el concepto de domesticación. En la primera parte del trabajo, se narran parte de los experimentos realizados con el fago phi 29 en un laboratorio del Centro de Biología Molecular del CSIC, para describir tres procesos distintos de domesticación. Y en la segunda, centrada en el estudio de los registros de los experimentos, se analiza la agencia de los cuadernos de laboratorio en los procesos de domesticación. Las formas que pautan los cuadernos, las voces que incluyen y los tiempos que en ellos quedan atrapados aportan información crítica y novedosa sobre los procesos de domesticación y sus significados.

Palabras clave: historia material de la ciencia; patentes; cuadernos de laboratorio; domesticación; ciencia reciente.

\begin{abstract}
In this article, repositories are proposed as subjects and epistemological objects to reflect on the concept of domestication. In the first part of the work, it is part of the experiments carried out with the work in the laboratory of the Molecular Biology Center of the CSIC, to describe the processes of domestication. In the second part, centered on the study of the records of the experiments, the agency of the laboratory notebooks

* Este trabajo se ha realizado en el marco del proyecto de investigación (FFI2016-76364) del Ministerio de Economía y Competitividad.
\end{abstract}


in the processes of domestication is analyzed.The norms that guide the notebooks, the voices that they include and the times (temporalities) that they incorporate, provide critical and novel information about the processes of domestication and their meanings.

Keywords: material history of science; patents; laboratory notebooks; domestication; recent science.

\section{Introducción}

Los cuadernos de laboratorio han sido un objeto de uso constante y común en los laboratorios a lo largo de la historia, pero no ha sido hasta los ańos ochenta del pasado siglo XX cuando han comenzado a recibir la atención de los investigadores y a ser objetos de estudio. El interés de los filósofos e historiadores de la ciencia que a lo largo de la primera mitad del siglo XX había estado centrado en conocer el por qué de las teorías científicas cambió en la década de los ochenta, influidos por los estudios sociológicos del conocimiento científico, por el interés por las prácticas y los procesos experimentales. Ese cambio, en el que se produjo el paso del qué al cómo, no solo ha visibilizado nuevos objetos con los que narrar la historia de la ciencia, también ha conectado espacios hasta entonces considerados dicotómicos (Wise, 2006).

Los trabajos pioneros realizados por Frederic L. Holmes sobre el químico Antoine Lavoissier y el bioquímico Hans Krebs, los de Mirko Grmek sobre el médico Claude Bernard, y los de Gerald L. Geison sobre el químico y bacteriólogo Louis Pasteur, llamaron la atención sobre estos materiales y los trajeron a un primer plano; los sacaron de los espacios donde habían sido generados y los dotaron de un nuevo significado (Holmes, 1987 y 1991; Grmek, 1991 y 1997; Geison, 1995). A la función que hasta entonces se les presumía, como contenedores y depositarios de la memoria de lo realizado en los laboratorios y la de ser utilizados, por ejemplo, como prueba o testigo de cargo en casos de litigio con una patente, los trabajos mencionados han convertido a estos materiales en objetos y sujetos de los estudios culturales de la ciencia y la tecnología; los cuadernos de laboratorio han pasado de ocupar el espacio de la nota a pie al cuerpo mismo del texto.

En este artículo propongo los repositorios científicos y el material en ellos contenido como objetos y sujetos epistemológicos para reflexionar sobre el concepto de domesticación. Si los ensayos en los laboratorios y las observaciones del campo ayudan a medir y modelar, ordenando y haciendo comprensible lo que Lorraine Daston llama primera naturaleza, los materiales que resultan de lo realizado en esos laboratorios conformarían una segunda naturaleza que, al ser seleccionados para ser guardados y perdurar en el tiempo devendrían, producto de un nuevo proceso de domesticación, en una tercera naturaleza: la contenida en los archivos y repositorios de la ciencia (Daston, 2017, 1-14). 
La principal fuente de este trabajo son los cuadernos de laboratorio que desde 2011 conforman el Fondo Margarita Salas depositado en el Centro de Ciencias Humanas y Sociales del CSIC. Un material situado en ese espacio amplio de interacción e hibridación, donde fuente documental y legado material están en constante diálogo y construyen un mismo patrimonio con el que narrar y escribir la historia de la ciencia reciente (Doel y Söderqvist, 2010; Harvey, 2009).

El trabajo con los cuadernos abre nuevos espacios donde narrar historias colectivas que conectan espacios hasta ahora distantes, donde los tiempos se superponen y en los que afloran también los retrocesos. Las pequeńas historias contenidas en estos materiales y los distintos agentes que incorporan, cuestionan las narraciones lineales de la ciencia, basadas en su mayoría en logros individuales, que solo exhiben éxitos y destacan la importancia que para el desarrollo de las prácticas científicas tuvo también el aprendizaje de los errores.

Decía Georges Canguilhem que conocer es analizar y destacaba la estrecha relación entre las nociones de experiencia y función: "Aprendemos nuestras funciones en las experiencias e inmediatamente nuestras experiencias pasan a ser funciones formalizadas" (Canguilhem, 1976, 7 y 23). En este sentido la domesticación, resulta de la necesidad y voluntad de experimentar y analizar, para someter y dominar, para conocer. La asunción de las bases del conocimiento científico - la experimentación, la deducción y la repetición - para explicar la domesticación de plantas y animales, esa primera naturaleza que menciona Daston, forma parte también de la construcción de esta metáfora.

Este artículo centrado en la segunda naturaleza de la que habla Lorraine Daston, tiene un doble propósito. Por un lado mostrar los procesos de domesticación del virus phi 29 que se dieron en el laboratorio de Margarita Salas y la materialización de sus resultados: 1) la obtención del ADN del virus, mediante técnicas de replicación de $\mathrm{ADN}$ en el tubo de ensayo - lo más parecido a la cría en cautividad-; 2) la consecución de una patente y 3) la producción de los kits con los que industrializaron y comercializaron los procesos. Tres resultados que fueron desarrollados en espacios culturales diferentes —el laboratorio, las oficinas de patentes y la industria-, y que la domesticación del virus conectó, diluyendo las fronteras entre ellos. Como expresa Kohler quizá en este caso sea más pertinente hablar de lindes (border) que de límites (boundary) (Kohler, 2002, 11-19). La metáfora de la domesticación se hace tangible tanto en la materialidad de los resultados como en la conexión y conquista de espacios culturalmente diferenciados (Wise, 2006).

Y la segunda propuesta es reflexionar sobre la agencia de los cuadernos de laboratorio en los procesos de domesticación. La reiteración y repetición de muchos de los experimentos que quedaron incorporados a los cuadernos sugieren, en palabras de Canguilhem, formas de dominio y control, de reclusión y aislamiento, de domesticación de prácticas y técnicas, que buscaban domar del virus. 
Propongo en definitiva las prácticas científicas, dentro y fuera de los laboratorios, y el análisis de sus registros para pensar el concepto de domesticación y la metáfora a él asociada en un sentido amplio (Rader, 2007, 183-204).

\section{El dominio de los laboratorios: la doma del virus}

El estudio de los virus que infectan bacterias ha servido desde la década de 1950, para conocer los procesos de transferencia de la información genética. Los términos utilizados para nombrar estos procesos, replicación, transcripción y traducción sugieren, si atendemos a los significados recogidos en los diccionarios de la lengua, reiteración y repetición; copia, duplicación y reproducción; interpretación, traslado, descifrado, cambio, conversión.

Los trabajos sobre el virus phi 29 realizados desde 1967 en el laboratorio de genética molecular que dirigió Margarita Salas en el Centro de Biología Molecular del CSIC, permiten que hoy conozcamos los procesos de replicación y transcripción del material genético $(\mathrm{ADN}$ y $\mathrm{ARN})$ y la forma en que se inicia la replicación del virus. $\mathrm{O}$ bien, que conozcamos los mecanismos que se usan para replicar y transcribir el material genético (ADN y ARN) en el laboratorio. La reiteración y la repetición como forma de conocer, de dominar el virus fue una constante en las prácticas de este laboratorio.

Los experimentos que con el virus del phi 29 habían sido realizados, descritos y publicados por distintos laboratorios, permitieron al grupo de Madrid repetirlos una y otra vez y obtener resultados diferentes. Bernard E. Rielly y John Spizizen primero y Anderson y Hickman después, habían descrito la estructura del Bacilus subtilis al que infecta el fago phi 29 y la longitud del ADN del fago (Rielly y Spizizen , 1965; Anderson, Hickman y Rielly, 1966). El grupo de Madrid conocía por tanto cómo habían purificado el virus, el uso que habían hecho del microscopio electrónico y cómo habían medido las moléculas de $\mathrm{ADN}$. Les quedaba por conocer cómo se producía la replicación y la transcripción - mecanismos por los que el ADN se duplica en el primer caso y por el que se genera el ARN en el segundo- , y la traducción del virus — proceso por el que se traslada la información contenida en la secuencia de $\mathrm{ADN}$ a las proteínas y para el que se emplea el ARN producido en la transcripción-.

En el origen de la investigación de este laboratorio del Centro de Biología Molecular del CSIC hay dos investigadores pioneros de la biología molecular en España: Margarita Salas y Eladio Viñuela. En 1964 ambos ya doctores habían viajado a Nueva York para continuar su formación en el laboratorio que Severo Ochoa tenía en la School of Medicine de la Universidad de Nueva York (Santesmases, 2005). Allí Margarita Salas trabajó sobre la dirección de lectura del mensaje genético y los mecanismos de iniciación de la síntesis de proteínas. Publicó los primeros resultados en 1965 en el Journal of Biological Chemistry (Salas et al., 1965). 
Cuando en 1967 regresaron a España pusieron en marcha un proyecto de investigación que traían ya diseñado de Estados Unidos. Conocedores como ya he mencionado del trabajo realizado por Anderson y Hickman (1966) que describía la morfología del virus y el tamaño del $\mathrm{ADN}$ de fago, eligieron este sistema para iniciar sus investigaciones en Espańa.

Contaron para ello con apoyo económico e institucional. El instituto Gregorio Marańón del Centro de Investigaciones Biológicas del CSIC creó para ellos dos secciones, una de Biología Molecular — que en 1970 se convertiría en departamento - bajo la dirección de Eladio Viñuela y otra de Genética Molecular al cargo de Margarita Salas (Centro de Investigaciones Biológicas, 1968, 61-62). La Jane Coffin Childs Memorial Foundation for Medical Research les concedió 6.000 dólares en 1967 y 15.000 en 1968. En 1970 la fundación norteamericana renovó su apoyo con 25.000 dólares más para los tres ańos siguientes (Centro de Investigaciones Biológicas, 1967, 62; Centro de Investigaciones Biológicas, 1968, 62; Centro de Investigaciones Biológicas, 1970, 77).

También en 1967 recibieron apoyo económico español: el Fondo Nacional para el Desarrollo de la Investigación Científica les concedió una subvención que ascendió a 2.303.485 pesetas (Centro de Investigaciones Biológicas, 1967, 62). Si tenemos en cuenta que el importe total de las subvenciones del Fondo en 1967 ascendió a cuarenta y dos millones de pesetas (ABC, 18 de agosto de 1967), esta ayuda mostraba por lo menos dos cosas: voluntad política por impulsar en España líneas de investigación en biología y genética moleculares, y confianza en los investigadores que las lideraban.

Las dotaciones económicas y de personal investigador —estos años fueron también los del II Plan de Desarrollo Económico y Social (1968-1971) que tuvo entre sus objetivos prioritarios el Plan de Formación de Personal Investigadorfortalecieron y ampliaron un espacio disciplinar que a partir de entonces no hizo más que crecer. Margarita Salas ha contado que la independencia en 1975 del Instituto Gregorio Marañón del CIB y la creación del Centro de Biología Molecular "Severo Ochoa", un proyecto que comenzó a gestarse a comienzos de los setenta en el campus de la Universidad Autónoma de Madrid, fue posible gracias a voluntades políticas decididas. Un apoyo que se justificaba por el prestigio que ambos investigadores ya tenían por el trabajo que habían realizado desde finales de los sesenta y también por la mediación de Severo Ochoa (Salas, 2005).

Los trabajos realizados desde finales de la década de los sesenta contenidos en los cuadernos del laboratorio y en las publicaciones, permiten reconstruir un relato en el que destacan tres momentos en ese camino por conocer y domesticar el virus.

El primer momento lo caracterizan los experimentos encaminados a conocer las proteínas del virus. En una publicación de 1971 que Enrique Méndez —el primer estudiante de postgrado que se incorporó al grupo- publicó, junto a 
otros investigadores del laboratorio, un trabajo que describía la estructura de la partícula viral y la caracterización de las diferentes proteínas que conformaban las distintas estructuras del fago (Méndez et al., 1971). En estos ańos se iniciaron también en el laboratorio experimentos sobre la genética del fago; buscaban aislar mutantes — virus diferentes a los demás — que fueran sensibles a altas temperaturas y a supresores que inhibieran que el fago se duplicara. La presencia de unas proteínas que, de forma transitoria, formaban parte de la partícula vírica pero que desaparecían en el fago maduro les llevó a estudiar la formación del virus y a detallar sus partes (Camacho et al., 1974; Moreno et al., 1974; Camacho et al., 1975; Mellado et al., 1976).

En 1976 el grupo de Margarita Salas incorporó al laboratorio la enzima de restricción EcoRI y comenzó a experimentar con ella; a partir de entonces pudieron reconocer secuencias de nucleótidos dentro de la molécula de ADN, cortar el $\mathrm{ADN}$ en un punto concreto y establecer por vez primera para el virus phi 29 la correlación entre la forma, las propiedades del virus y su ADN (Inciarte et al., 1976). El uso de esta enzima en el laboratorio espańol, cuyo descubrimiento en Estados Unidos marcaría el origen de la biotecnología, sugiere prácticas y experimentos contemporáneos similares a los que se estaban haciendo en los laboratorios estadounidenses (sobre los comienzos del uso de los enzimas de restricción ver Wright, 1994).

El segundo momento de la domesticación del virus lo marcaron las investigaciones que buscaban entender los procesos de la transcripción y los mecanismos por los que se producía la replicación. De 1970 data el primer trabajo del laboratorio sobre el estudio de la transcripción del ADN del fago (María Jesús Santesmases, 2006). En él se identificaban cuatro subunidades de un ARN polimerasa, implicadas una en la iniciación de la transcripción y las otras tres en el proceso de elongación. Posteriormente otros trabajos demostraron la existencia de un control temporal en la transcripción del ADN del virus: había genes tempranos que se expresaban al comienzo de la infección y genes tardíos que se transcribían posteriormente (Ávila et al., 1970). Fue entonces cuando descubrieron una proteína que participa activamente en la regulación del proceso. Esa proteína que transfería al ARN la información genética almacenada en el ADN, activaba, al mismo tiempo ciertos promotores en el ADN del virus y reprimía e inhibía otros. Margarita Salas conocía bien cómo funcionaban los mecanismos de iniciación. En el laboratorio de Ochoa en Nueva York había investigado sobre la dirección de lectura del mensaje genético y el mecanismo de iniciación de la síntesis de proteínas (Santesmases, 2001, 2005 y 2006). Esta experiencia explica el descubrimiento de una proteína del fago, que llamaron proteína terminal que después consideraron responsable de la iniciación de la replicación de DNA del fago (Ortín et al., 1971). Imágenes del microscopio electrónico confirmaron su presencia en los dos extremos del fago lo que sugería que la iniciación de la repli- 
cación del ADN del virus podría producirse en cualquiera de los dos extremos: esto supuso el descubrimiento del mecanismo de iniciación de la replicación del ADN lineal ${ }^{1}$.

El descubrimiento de esta proteína terminal responsable de la iniciación de la replicación del $\mathrm{ADN}$ fue otro de los logros de este laboratorio que produjo la domesticación del virus. Con ello mostraban un mecanismo particular: el inicio de la replicación mediante una proteína unida directamente al ADN. Este descubrimiento fue utilizado posteriormente para estudiar otros virus de interés sanitario como el adenovirus, el poliovirus, el virus de la hepatitis $\mathrm{C}$ y el de la fiebre aftosa.

Por último, el tercer momento en ese camino hacia la domesticación del virus, fue conocer que el fago phi 29 sintetizaba una $\mathrm{ADN}$ polimerasa propia y que sus características eran las adecuadas para amplificar su material genético.

El primer resultado de la doma del virus fue reproducir en un tubo de ensayo el mecanismo de replicación del ADN del fago (Blanco y Salas, 1984; Blanco et al., 1989). Conociendo que el mecanismo de replicación del ADN del fago phi 29 se amplificaba — copiaba - unas 1000 veces in vivo, pasaron a estudiar si esa misma amplificación era posible en el tubo de ensayo. Para ello utilizaron cuatro proteínas virales que sabían eran esenciales para la replicación del $\mathrm{ADN}$ del virus (TP, ADN polimerasa, p5 ó SSB, y p6 ó DBP). Los experimentos dieron como resultado que el $\mathrm{ADN}$ amplificado en el tubo de ensayo contenía el del phi 29 y, lo que era más importante, que se había amplificado o copiado con una gran fidelidad (Blanco et al., 1994). Este primer objeto de la domesticación sugiere y evoca la cría en cautividad.

El segundo resultado de la domesticación del virus fue la solicitud y obtención de patentes. Si el primer dominio del virus se produjo en el espacio del laboratorio este segundo resultado, que exhibe el dominio del virus en forma de innovación, se dio en un espacio culturalmente muy diferente: el de las oficinas de patentes.

En la presentación en 1988 de parte de la investigación del laboratorio en un Workshop organizado por la European Molecular Biology Organization (EMBO) celebrado en Salamanca, Margarita Salas y Charles Richardson hablaron por primera vez de patentar. Charles C. Richardson era investigador del Departamento de Química Biológica y Farmacología Molecular de la Medical School de Harvard y asesor científico de la empresa americana United Status Biochemical Coorporation (USB). En ese momento estudiaba la proteína ADN polimerasa con otro fago y conocía bien los resultados de la investigación del

\footnotetext{
${ }^{1}$ Las bacterias, como los bacilos, son células procariotas que tienen ADN circular. Las células eucariotas, las que tenemos el resto de los seres vivos, tienen $\mathrm{ADN}$ lineal.
} 
grupo de Salas. Richardson llevaba tiempo siguiendo las publicaciones del laboratorio español y por ello les planteó las posibles aplicaciones que podían tener los estudios y las características de la ADN polimerasa del fago phi 29.

La investigación que se estaba desarrollando en Estados Unidos en este campo muestra el origen del interés de Richardson por la investigación del grupo español. De 1985 data el primer artículo sobre la técnica de la PCR (Polymerase Chain Reaction), uno de los textos de referencia que sería incluido en la patente que redactaron en estrecho diálogo con los investigadores norteamericanos. En ese trabajo un grupo de científicos liderados por Kary Mullis describía esta técnica que permite iniciar y detener la acción de una polimerasa en puntos específicos de una cadena de $\mathrm{ADN}$ o lo que es lo mismo, permite que un fragmento de ADN seleccionado pueda ser amplificado de forma exponencial. La mejora de esta técnica entre 1985 y 1989 la convirtieron en una herramienta de gran utilidad para la biología contemporánea. En 1993 Kary Mullis recibió el premio Nobel de química, compartido con Michael Smith, por el invento de esta técnica (sobre Kary Mullis ver, Rabinow, 1996; Mullis, 1998; García-Sancho, 2012, $160-162$ y 200).

La primera patente que redactaron, "Reacciones de síntesis de ADN (in vitro) que emplean ADN polimerasa de Phi 29 modificada y un fragmento de ADN que codifica dicha polimerasa" fue solicitada en la Oficina de Patentes de Estados Unidos y concedida en marzo de 1989. Como inventores de la patente figuraban Luis Blanco —entonces Colaborador Científico del CSIC- Antonio Bernad —entonces becario predoctoral — y Margarita Salas; como propietario figuraba el Consejo Superior de Investigaciones Científicas, organismo público de investigación al que pertenecía el Centro de Biología Molecular². El documento destacaba, como usos directos de la invención, los trabajos forenses, donde disponen de pequeñas muestras de $\mathrm{ADN}$ que la enzima permitiría amplificar y los análisis de polimorfismo (Lynch y Jasanoff, 1998).

Tras la aprobación de la patente en la Oficina de Estados Unidos, en marzo de 1990 se solicitó su introducción en el sistema PCT (Patent Corporation Treaty, Tratado de Cooperación en materia de Patentes), una solicitud que se hizo pública en octubre de $1991^{3}$.

\footnotetext{
2 Phi29 DNA polymerase, Patent US5001050. United State Patent Office Archive.

${ }^{3}$ El sistema PCT fue una iniciativa norteamericana diseñada para proteger, a nivel mundial las patentes de cualquier país miembro. Firmado en Washington en 1970 y gestionado por la Organización Mundial de la Propiedad Intelectual (OMPI), actualmente cuenta con el respaldo de más de 140 países. La incorporación de España al sistema PCT se hizo efectiva en noviembre de 1989. Este sistema que permite realizar solicitudes de protección a nivel internacional de forma conjunta (evita tener que hacer solicitudes individuales de patentes en cada uno de los países) ha sido, desde mediados de los noventa ampliamente utilizado por universidades y centros públicos de investigación espańoles.
} 
En 1993 la patente "An improved method for determining the nucleotide base sequence of a DNA molecule" fue solicitada en la Oficina Europea de Patentes y concedida cuatro años más tarde, en 1997. En agosto de este mismo año, finalmente, la patente pasó a tener efecto también en Espańa (para una historia de esta patente como agente diplomático y mediador ver Romero de Pablos, en prensa).

Tras un largo viaje, desde el laboratorio a la industria, pasando por foros científicos de discusión y oficinas de patentes, un conjunto de técnicas y prácticas originadas en un laboratorio español, producto de nuevos procesos de domesticación volvían a España, protegidas, estandarizadas, normalizadas y legitimadas. El conjunto de técnicas y prácticas que tenían por objeto el control del virus Phi 29 quedaban contenidas en una patente que controlaba y regulaba su paso a la industria.

La patente otorga derechos exclusivos al propietario de la misma para explotar comercialmente durante 20 años la tecnología reivindicada en la patente. Por lo tanto no solo sugiere la domesticación del conocimiento contenido en ella sino también el control de su explotación.

El tercer fruto de la domesticación del virus phi 29 fueron los dos kits o estuches con los elementos necesarios para hacer una PCR, o lo que es lo mismo duplicar un fragmento de ADN, que fueron puestos en el mercado. En el año 1989 el CSIC concedió a la empresa USB — posteriormente absorbida por Amersham Biosciences - la licencia de explotación de la patente. Esta empresa desarrolló en 2001 un kit para amplificar ADN circular (TempliPhi) y después en 2003 otro para amplificar ADN lineal (GenomiPhi). Fue una patente exitosa: hasta 2009 año en que permaneció viva la patente el 50 por ciento de los pagos totales que recibió el CSIC por derechos de explotación, procedían de esta patente. Además, los trabajos que han seguido realizando en este laboratorio para mejorar la ADN polimerasa de phi 29 han dado nuevos resultados: han patentado otro sistema de amplificación de DNA, utilizando la proteína terminal, y también la señal de localización nuclear de la proteína terminal.

La historia de la ADN polimerasa del virus phi 29 muestra procesos de domesticación complejos con interesantes resultados en el campo de las aplicaciones biotecnológicas. La metáfora de la domesticación se hace tangible no solo en los objetos producto de la misma sino también en los espacios culturales - el laboratorio y fuera de él一, en los que se desarrolla.

\section{El dominio del registro: los cuadernos de laboratorio}

Frederic L. Holmes y Gerald L. Geison coincidieron en llamar la atención en la distancia existente entre lo recogido en los cuadernos de laboratorio y lo expresado en los textos científicos y demás narraciones que a posteriori se hacían 
de los experimentos. Ese foco en las discrepancias y diferencias entre unos y otros documentos, entre los "datos en bruto" y su transformación en resultados, abre un espacio interesante donde trabajar y pensar sobre el conocimiento que, producto de los procesos de domesticación, se hace público y por qué, los agentes intervienen y en qué circunstancias. La brevedad, la claridad, la coherencia, características expresadas como virtudes que a menudo acompañan las ciencias y sus prácticas, son algunas de las explicaciones que Holmes ha contemplado para explicar que en ocasiones las publicaciones científicas no siempre recojan y reproduzcan fielmente los procesos y los resultados tal y como fueron desarrollados en los laboratorios. La mirada etnográfica de Bruno Latour y Steve Woolgar en La vida en el laboratorio (1987) advertía también sobre cómo los hechos eran producto de la domesticación de los haceres, técnicos y lingüísticos, de los propios científicos.

Los dibujos, las fotografías y otras formas de registro contenidos en los cuadernos son representaciones que construyen y participan de los procesos de domesticación. Son materiales que responden a momentos, experiencias y espacios concretos en los que van tomando forma. Esas formas que marcan y pautan los cuadernos, las voces que incluyen y los tiempos que en ellos quedan atrapados aportan una información crítica y novedosa que visibilizan otros factores que participan de los procesos de domesticación y amplían sus significados.

Los cuadernos, poblados de dudas, retrocesos y contradicciones, ofrecen una aproximación distinta a las prácticas investigadoras. Las preguntas, los problemas, los instrumentos utilizados, los procesos experimentales y las interpretaciones posibles, son algunos de los elementos presentes en los cuadernos de laboratorio que evocan procesos de domesticación. Todos ellos, de forma individual o conjunta, insertos en esa segunda naturaleza de la que habla Lorraine Daston, construyen pequeños procesos de domesticación que al ponerlos en diálogo con procesos y desarrollos científicos más amplios nos permiten hacer narraciones con mayor proyección en el tiempo y el espacio (Bresadola, 2003; Holmes, Renn y Rheinberger, 2003).

Las voces que encontramos en los cuadernos de laboratorio son distintas a las empleadas en los escritos públicos. Frente al uso, en artículos científicos y patentes, del infinitivo y de oraciones impersonales que ocultan las voces y con ellas a los actores de los procesos, pero que potencian la idea del carácter neutral de los experimentos científicos, los cuadernos incluyen anotaciones donde la autoría está presente a través de la voz en tercera persona. Mientras que en el primer caso los instrumentos, geles y parafinas parecen actuar y tener agencia propia, el uso de la tercera persona no solo dota de agencia a los sujetos, también exhibe la vulnerabilidad de los mismos, visibiliza las voluntades e intenciones que mueven la toma de decisiones, mostrando las prácticas de los laboratorios, no son en absoluto neutrales. Los cuadernos, normalmente de autoría individual, incorporan en ocasiones voces de otros miembros del grupo de investigación que 
corrigen, comentan y cuestionan pasos dados en un experimento o incluso los propios resultados. Estas voces que registran formas de control tan comunes en los laboratorios, sugieren también voluntad de dominio de los procesos de enseńanza y aprendizaje. Las aportaciones individualidades de los cuadernos cobran significado al sumarse a las voces de los otros cuadernos. Una pluralidad de voces que construyen la biografía colectiva del laboratorio y que sugieren procesos de domesticación colectivos no solo dirigidos a dominar el virus, también las técnicas y procesos de aprendizaje de los grupos de investigación.

Al igual que las voces, los tiempos que reflejan los cuadernos son distintos en función del uso que hagamos de los mismos. Hans Jörg Rheinberger en su análisis del concepto del tiempo biológico habló de la existencia de diferentes temporalidades (differential temporalities) para pensar el desarrollo del conocimiento en las ciencias de la vida, sus tiempos biológicos y la combinación con los históricos (Müller-Wille y Rheinberger, 2012). Los tiempos que exhiben los cuadernos del laboratorio de Margarita Salas, son los tiempos experimentales. Junto al registro día a día de un único tiempo, continuo y sin aparente interrupción, convive el que muestra secuencias y momentos, marcados por los tiempos que imponen a los experimentos el funcionamiento de los instrumentos y los que, por el contrario, marcan los experimentos y condicionan incluso el desarrollo de instrumentos. Estos tiempos híbridos que menciona Christina Brandt cuando introduce, al hablar de evolución, los tiempos que duran los experimentos (Bran$\mathrm{dt}, 2013)$, sugieren discontinuidades, vueltas al pasado y procesos en ocasiones inacabados. Unos tiempos pequeńos, fragmentados, que sugieren causalidades y donde la dilación y la reiteración hablan de las dificultades que entrañan los procesos de domesticación, y de nuevo no siempre se corresponden con lo que transmiten los textos publicados. Este protagonismo del tiempo experimental, como variable en los experimentos y como memoria y registro de las prácticas diarias de los laboratorios, está prácticamente ausente en los trabajos que exhiben y hacen públicos los resultados. Aunque paradójicamente la línea temporal que traza la vida de un laboratorio, sus hitos, se dibuje en función de esos resultados públicos, también es cierto que la ausencia de la temporalidad oculta de nuevo identidades y esfuerzos — no es lo mismos conseguir algo en un tiempo que en otro- Visibilizar las muchas discontinuidades y retornos en el tiempo que se dan en las prácticas científicas, sugieren procesos de domesticación más complejos y que tienen poco diálogo con narraciones lineales del desarrollo científico que buscan reforzar la idea de progreso.

Los dibujos, fotografías y demás formas de registro contenidos en los cuadernos, las voces y los tiempos, recogen el detalle experimental de las prácticas que ensayan y los modelos que les inspiran. Los hallazgos, los métodos, las técnicas, y también los resultados en ellos referenciados hacen posibles otras reflexiones sobre los procesos de domesticación en las prácticas de la biología contemporánea. Unos procesos que junto a logros muestran también incertidumbre, decepciones, caminos iniciados y no concluidos. 
Decía al comenzar que las prácticas de laboratorio y el análisis de sus registros los iba a utilizar para reflexionar sobre el concepto de domesticación en un sentido amplio. Por ello no debemos pensar sobre procesos de domesticación, sin pensar también en valores, intenciones, reglas, normas, medios y formas de comunicación, conductas y prácticas no solo experimentales. Las historias recogidas en estos materiales amplían el significado del concepto domesticación e impiden pensarlo como un proceso lineal. Los casos aquí narrados muestran que fueron desarrollos complejos, que ocuparon diferentes escenarios - científicos, políticos $\mathrm{y}$ administrativos - , que fueron producto de trabajos colectivos - investigadores y gestores - y en los que participaron distintos agentes. Fue una domesticación que no solo se produjo en los espacios de los laboratorios, también fuera de ellos.

Estos registros ponen sobre la mesa dos problemas sobre los que estamos pensando quienes historiamos, hacemos historia material, de la ciencia y la tecnología: la necesidad de pensar sobre los registros de la práctica científica contemporánea y cómo guardarlos (Lewenstein, 2010) y el conflicto entre memoria e historia (Hoddeson, 2010). El traslado, ordenación, conservación y custodia de estos cuadernos ha puesto de manifiesto que, además de estar obligados a pensar otras formas de archivo — la ciencia en los archivos-, debemos también reflexionar sobre la pérdida que supone limitar la vida de estos materiales a los laboratorios y los silencios y ausencias que esto supondría para relatos futuros de la ciencia y la tecnología. Historizar y problematizar las prácticas científicas, las formas de registrarlas y conservarlas nos enfrenta a nuevos desafíos y abre otros caminos útiles para pensar nuevas formas de narrar la ciencia reciente.

\section{Referencias bibliográficas}

Anderson, D. L., D. D. Hickman, and Reilly, Berbard E. (1966). Structure of Bacillus Subtilis Bacteriophage Phi 29 and the Length of ø29 Deoxyribonucleic Acid. Journal of Bateriology, 91, 2081-2089.

Ávila, Jesús, Hermoso, J.M.; Viñuela, E.; Salas, M. (1970). Subunit Composition of B. Subtilis RNA Polimerase, Nature, 226, 1244-1245.

Blanco, Luis, Salas, Margarita (1984). Characterization and Purification of a Phage Phi 29-Encoded DNA Polymerase Required for the Initiation of Replication. Proceedings of the National Academy of Sciences of the United States of America, 81(17), 5325-9.

Blanco, Luis, Bernad, Antonio, Lázaro, José M., Martín, G., Garmendia, Cristina y Salas, Martgarita (1989). Highly Efficient DNA Synthesis by the Phage $\varnothing 29$ DNA Polymerase. Symmetrical Mode of DNA Replication. Journal of Biological Chemistry, 264, 8935-8940. 
Blanco, Luis, Lázaro, José M., de Vega, Miguel, Bonnin, Ana y Salas, Margarita (1994). Terminal Protein-Primed DNA Amplification. Proceedings of the National Academy of Sciences of the United States of America, 91(25), 12198-12202.

Camacho, Ana, Moreno, Felipe; Carrascosa, José L.; Viñuela, Eladio; Salas, Margarita (1974). A Suppressor of Nonsense Mutations in Bacillus subtilis. European Journal of Biochemistry, 47,199-205.

Camacho, A., Carrascosa, J.L., Viñuela, E., Salas, M. (1975). Discrepancy in the Mobility of a Proteína of Phage Phi 29 in Two Different SDS-Polyacrylamide Gel Systems. Analytical Biochemistry, 69, 395.

Canguilhem, Georges (1976). El conocimiento de la vida. Barcelona: Editorial Anagrama.

Centro de Investigaciones Biológicas, Memoria (1967). Madrid: CSIC, 1968, http://digital.csic.es/bitstream/10261/39212/1/Memoria_CIB_1967.pdf

Centro de Investigaciones Biológicas, Memoria (1968). Madrid: CSIC, 1969, http://digital.csic.es/bitstream/10261/39214/1/Memoria_CIB_1968.pdf

Centro de Investigaciones Biológicas, Memoria (1970). Madrid: CSIC, 1971, http://digital.csic.es/bitstream/10261/39272/1/Memoria_CIB_1970.pdf

Daston, Lorraine (ed.) (2017). Science in the Archives. Pasts, Presents, Futures. Chicago y London: The University of Chicago Press.

Doel, Ronald E. y Söderqvist, Thomas (eds.) (2010). The Historiography of Contemporary Science, Technology, and Medicine. Writing recent Science. London $\&$ New York: Routledge.

García-Sancho, Miguel (2012). Biology, Computing, and the History of Molecular Sequencing. From Proteins to DNA, 1945-2000. Londres: Palgrave Mcmillan.

Geison, Gerald L. (1996). The Private Science of Louis Pasteur. Princeton, New Jersey: Princeton University Press.

Grmek, Mirko (1991). Claude Bernard et la méthode expérimentale. Paris: Payot.

Grmek, Mirko (1997). Le legs de Claude Bernard. Paris: Fayard.

Harvey, Karen (ed.) (2009). History and Material Culture. A student's guide to approaching alternative sources. London \& New York: Routledge.

Hoddeson, Lillian (2010). The Conflict of Memoires and Documents: Dilemmas and Pragmatics of Oral History. En Ronald E. Doel y Thomas Söderqvist (eds.), The Historiography of Contemporary Science, Technology, and Medicine. Writing recent Science (pp. 187-200). London y New York: Routledge. 
Holmes, Frederic L. (1987). Lavoisier \& The Chemistry Of Life. Wisconsin: University of Wisconsin Press.

Holmes, Frederic L. (1998). Antoine Lavoisier: The Next Crucial Year: Or, the Sources of His Quantitative Method in Chemistry. Princeton, New Jersey: Princeton University Press.

Inciarte, MartaR.; Lázaro, José M.; Salas, Margarita; Viñuela, Eladio (1976). Physical Map of Bacteriphage phi 29. Journal of Virology, 74 314-323.

Kohler, Robert (2002). Landscapes and Labscapes. Exploring the Lab-Field Border in Biology. Chicago: University of Chicago Press.

Lewenstein, Bruce V. (2010). The History of Now: Rflections on Being a 'Contemporary Archivist'. En Ronald E. Doel, y Thomas Söderqvist (eds.), The Historiography of Contemporary Science, Technology, and Medicine. Writing recent Science (pp. 31-42). London y New York: Routledge.

Mellado R.P., Moreno F., Viñuela E, Salas M., Reilly B.E., Anderson D.L. (1976). Genetic Analysis of Bacteriophage Phi 29 of B. Subtilis: Integration and Mapping of Reference Mutants of Two Collections. Journal of Virology, 19: 495-500.

Méndez, Enrique, Ramírez, G.; Salas, Margarita, Viñuela, Eladio (1971). Structural Proteins of Bacteriophage phi 29. Journal of Virology, 45, 567-576.

Moreno, F.; Camacho, A.; Viñuela, E.; Salas, M. (1974). Suppressor-Sensitive Mutants and Genetic Map of Bacillus subtillis phi 29. Virology, 62, 1-16.

Müller-Wille y Rheinberger. (2012). A Cultural History of Heredity. Chicago: The University of Chicago Press.

Mullis, Karry (1998). Dancing Naked in the Mind Field. New York: Vintage.

Ortín, J.; Vińuela, E.; Salas, M.; Vázquez, C. (1971). DNA-Protein Complex in Circular DNA from Phage phi 29. Nature New Biology, 234, 275-277.

Rabinow, Paul (1996). Making PCR. A Story of Biotechnology. London: University of Chicago Press.

Rader, Karen (2007). The Metaphor of Domestication in Genetics. En Rebeca Cassidy y Molly Mullin (eds.), Where the Wild Things are Now: Domestication Reconsidered (pp. 183-204). Oxford: Berg Publishers.

Reilly, Berbard E. y Spizizen, John (1965). Bacteriophage Deoxyribonucleate Infection of Competent Bacillus Subtilis. Journal of Bateriology, 60, 782790 .

Romero de Pablos, Ana (en prensa). Mediation and Harmonization: Construction of the Spanish Patent System in the Twentieth Century. En Graeme 
Gooday and Steven Wilf (eds.), Fashioning Global Patent Cultures: Diversity and Harmonization in Historical Perspective. Cambridge: Cambridge University Press.

Salas, Margarita, Smith, Marvin A., Stanley Jr., Wendell M., Wahba, Albert J. y Ochoa, Severo (1965). Direction of Reading of the Genetic Message. The Journal of Biological Chemistry, 240, 3988-3995.

Salas, Margarita (2005). La creación del Centro de Biología Molecular Severo Ochoa. En Ochoa y la Ciencia en España (pp.163-174). Madrid: Sociedad Estatal de Conmemoraciones Culturales, Residencia de Estudiantes.

Santesmases, María Jesús (2005). Severo Ochoa. De músculos a proteínas. Madrid: Síntesis.

Santesmases, María Jesús (2006). Peace, Propaganda and Biomedical Experimentation: Influential Uses of Radioisotopes in Endocrinology and Molecular Genetics in Spain (1947-1971). Journal of the History of Biology, 39(4), 765-794.

Wise, Norton (2006). Making Visible. Isis, 97(1), 75-82.

Wright, Susan (1994). Molecular Politics: Developing American and British Regulatory Policy for Genetic Engineering, 1972-1982. Chicago: The University of Chicago Press. 